\title{
Evidence-based pharmacological management of chronic neuropathic pain
}

\author{
Zarrin Ansari
}

Medical Advisor, Cipla Ltd., Mumbai Central, Mumbai400008, Maharashtra, India

Received: 2 April 2013

Accepted: 14 April 2013

\section{*Correspondence to:}

Dr. Zarrin Ansari,

Email: zarrin.ansari@cipla.com; zarrinansari@gmail.com

\section{(C) 2013 Ansari Z. This is an} open-access article distributed under the terms of the Creative Commons Attribution License, which permits unrestricted use, distribution, and reproduction in any medium, provided the original work is properly cited.

\begin{abstract}
Neuropathic pain (NP) is a chronic, debilitating symptomatology of lesions/injuries of the central and peripheral nervous system. As per pooled estimates, the prevalence is $7-8 \%$ in the general population; however, the prevalence varies with different neuropathic conditions. The aetiology can range from peripheral neuropathic conditions viz. peripheral diabetic neuropathic pain (PDNP), post-herpetic neuralgia (PHN), trigeminal neuralgia, HIV-associated polyneuropathy, cervical radiculopathy to central neuropathic conditions, viz. central post-stroke pain, spinal cord injury and the neuropathic pain associated with multiple sclerosis. Apart from the symptomatic perception of pain, neuropathic pain affects the cognitive and emotional aspects of the affected individual. The pain, being debilitating and resistant to over-the-counter analgesics, diminishes the quality of life, disrupts sleep and leads to psychiatric complications such as comorbid anxiety and depression. The management is palliative and involves drugs, psychological intervention, stimulations and nerve-blocking techniques. This review concentrates on the pharmacological therapeutic options available and focuses on the selection of the agent/s in accordance with the evidence. The first-line treatment includes the tricyclic antidepressants ([TCAs]; amitriptyline, nortriptyline), selective serotonin norepinephrine inhibitors ([SNRIs]; duloxetine, venlafaxine), calcium channel alpha 2 - delta ligands (pregabalin, gabapentin), carbamazepine and oxcarbazepine. Lidocaine plasters are first-line options for specific focal conditions such as post-herpetic neuralgia. The second-line therapy includes the opioid analgesics and tramadol. The choice of drug selection should complement the patient's age, type of neuropathic condition, tolerability to an agent, comorbid condition and cost-effectiveness. Management must be individualized with a realistic and composite goal of making the pain tolerable and improving the cognitive and emotional well-being.
\end{abstract}

Keywords: Neuropathic pain, Neuralgia, Pharmacological management, Algorithm, Analgesic agents, Evidence-based, Diabetic peripheral neuropathy

\section{INTRODUCTION}

Chronic pain, defined as daily pain over more than 3 months, is commonly encountered in medical practice. Pain can be a presentation of a wide-spectrum of aetiology and pathophysiology. For better understanding it can be classified into two categories: nociceptive pain and neuropathic pain. Nociceptive pain is primarily because of stimulation of the nociceptors due to external tissue injury. It is a protective pain as it signals the perceiver to protect the tissue from damage. On the contrary, neuropathic pain is a spontaneous pain due to an injury or a lesion in the nervous system. The International Association for the Study of Pain (IASP) defines neuropathic pain as "pain arising as a direct consequence of lesion or disease of the somatosensory nervous system." It is often severe, disabling and resistant to over-the-counter analgesics and is often associated with comorbid depression, anxiety, sleep disorders, impairment in the quality of life and increased health care cost. Neuropathic pain has no clinical benefit and is maladaptive. ${ }^{1,2}$

The nervous system is broadly classified into central and peripheral nervous system, and lesions of various aetiologies affecting either system can lead to neuropathic pain. The common neuropathic conditions affecting the peripheral nervous system include peripheral diabetic neuropathic pain (PDPN), postherpetic neuralgia (PHN), AIDS polyneuropathy, cervical or lumbar radiculopathy, mechanical compression such as 
entrapment syndromes (e.g. carpal tunnel syndrome), phantom limb pain after amputation, trigeminal neuralgia and traumatic nerve injury. Central causes for neuropathic pain include spinal cord injury (SCI), multiple sclerosis (MS) and stroke leading to central poststroke pain (CPSP)., ${ }^{9,15}$

\section{CLINICAL DESCRIPTION OF NEUROPATHIC PAIN}

According to a survey, the six adjective commonly used to describe the pain of neuropathic nature are electric shock (53\%), burning (54\%), tingling (48\%), cold, pricking and itching. These terms should suggest a neuropathic aetiology for pain. The pain may vary in intensity (mild, moderate, or severe), quality (sharp, burning or dull), duration (transient, intermittent or persistent), and referral (superficial or deep, localized or diffuse). Some specific signs and symptoms associated with neuropathic pain are allodynia (pain due to nonnoxious stimulus); anaesthesia (loss of normal sensation); dysaesthesia (spontaneous or evoked unpleasant abnormal sensation); hyperalgesia (exaggerated response to a mildly noxious stimulus); hyperpathia (delayed and explosive response to a noxious stimulus); hypoesthesia (reduction in normal sensation) and paraesthesias (abnormal sensations such as tingling and numbness). Though the description of pain is often with respect to its physical sensation component, the strong cognitive and emotional aspects challenge the quality of life of the affected individual. ${ }^{11}$

\section{EPIDEMIOLOGY OF VARIOUS NEUROPATHIC PAIN CONDITIONS}

Two large national surveys estimated that chronic pain of predominantly neuropathic in origin afflicts $7-8 \%$ of general population. ${ }^{3-5}$ However, the prevalence of neuropathic pain varies with the etiology. Peripheral diabetic neuropathy (PDN) is estimated to affect $20 \%$ to $24 \%$ of persons with diabetes and the condition is painful in $15 \%$ of persons with diabetes. ${ }^{6,10}$ The prevalence of PDN is known to be associated with poor glycemic control and increases both with age of the patient and duration of diabetes. ${ }^{7,8}$ The prevalence is estimated to be $5 \%(3.1-6.9 \%)$ in the 20-29 years of age group and $44.2 \%$ (41.1-47.3\%) in the 70-79 years of age group. In patients with diabetes duration less than 5 years, the prevalence of PDN is estimated to be $20.8 \%(19.1-22.5 \%)$ and is $36.8 \%(34.9-38.7 \%)$ in those with diabetes duration greater than 10 years. ${ }^{7,8}$ The prevalence of PDN is expected to rise with the rise in the prevalence of diabetes over the next two decades. Post herpetic neuralgia (PHN), defined as pain at 3 months after the rash is estimated to affect $7-27 \%$ of patients with herpes zoster. The risk of $\mathrm{PHN}$ increases with increasing age. Its prevalence is $25 \%$ to $50 \%$ in adults older than 50 years of age. , $10^{\text {Distal }}$ sensory neuropathy is a common complication of AIDS. The cause of HIV-associated polyneuropathy is multifactorial and it could be secondary to the HIV virus or the antiretroviral drug toxicity. The prevalence of HIV- associated polyneuropathy is $30-63 \%$ in HIVpositive patients. ${ }^{9,10}$ Amongst the central neuropathic pain conditions, central post stroke pain, a sequel of stroke is estimated to affect $8 \%$ to $11 \%$ of patients with stroke. The prevalence of neuropathic pain in patients with spinal cord injury is $10 \%$ to $80 \%$, whereas, in patients with multiple sclerosis is $23 \%$ to $58 \% .^{10}$

\section{GENERAL CONSIDERATIONS FOR MANAGEMENT}

Identifying the underlying disease process, location of lesion (central or peripheral nervous system), response to prior therapies and comorbid conditions affecting the patient should be the focus of the assessment of chronic neuropathic pain. Non-pharmacological management, which includes relaxation techniques, physical therapy, good sleep hygiene and interventional methods, can be considered at any stage of management. When choosing a medication, it is important to consider factors viz. underlying etiology, comorbid conditions (e. g. sleep disturbance, depression and anxiety), potential side-effects of the medication chosen, risk of intentional and unintentional overdose, medication abuse and costeffectiveness. The effectiveness of all medications is unpredictable, dosing can be complex and the onset of action may be variable. Given the diversity in the underlying etiology and response of the patients, treatment must be individualized and often more than a single agent is required for analgesia. A well communicated treatment goal of making the pain 'bearable or tolerable' rather than complete elimination of pain plays a crucial role in patient satisfaction towards treatment. ${ }^{12-14}$

\section{EVIDENCES AND RECOMMENDATIONS FOR PHARMACOTHERAPY}

\section{Painful Diabetic Peripheral Neuropathy (PDPN)}

Based on systematic review of the literature and randomized controlled trials, the European Federation of Neurological Societies (EFNS) recommends TCAs, gabapentin, pregabalin and SNRIs (duloxetine, venlafaxine) as the first-line treatment for PDNP. Tramadol is recommended as second-line except for patients with exacerbations of pain (for the tramadol/ acetaminophen combination) or those with predominant coexisting non-neuropathic pain (in view of its largely established efficacy in nociceptive pain). Third-line therapy includes strong opioids because of concerns regarding their long-term safety including addiction potential and misuse. ${ }^{15}$ Pregabalin is established as effective in lessoning the pain of peripheral diabetic neuropathy. It also improves the quality of life and lessens sleep interference. Some agents with not established efficacy in PDNP are capsaicin cream, oxcarbazepine, topiramate, lamotrigine, lacosamide, clonidine, pentoxyfylline and mexiletine. ${ }^{15-17}$ 


\section{HIV associated polyneuropathy}

Robust evidence for pharmacotherapy of HIV associated polyneuropathy is lacking and it is inappropriate to extrapolate data from randomized controlled trials done on other neuropathic conditions. Drugs known to be effective for the treatment of other neuropathic condition viz. TCAs, pregabalin, gabapentin have failed to demonstrate efficacy in HIV neuropathic pain. ${ }^{15}$ Lamotrigine has demonstrated modest efficacy and tolerability in patients with HIV associated polyneuropathy receiving neurotoxic antiretroval therapy. ${ }^{27}$ A single high-concentration capsaicin patches has shown sustained 12 weeks of pain reduction in HIV- associated polyneuropathy. ${ }^{28}$ Randomized controlled trials have demonstrated positive results for cannabis smoking, however, administration of cannabis smoking for a long term has high addictive potential and associated health risk. ${ }^{25,26}$

\section{Post herpetic neuralgia (PHN)}

TCAs or gabapentin/pregabalin have demonstrated efficacy for the treatment of PHN and are recommended as first-line treatment by the EFNS guidelines. ${ }^{15}$ Topical lidocaine may be considered first line in the elderly, especially if there are concerns regarding the central nervous system side effects of oral medications. Strong opioids and capsaicin creams/patches are recommended as a second choice. Capsaicin patches are promising, but the long-term effects of repeated applications particularly on sensation are not clarified. Agents with less/not established efficacy with PHN are benzylamide topical treatment, dextromethorphan, fluphenazine, memantine, lorazepam and mexiletine. ${ }^{15-17}$

\section{Trigeminal Neuralgia (TN)}

Carbamazepine and oxcarbazepine are confirmed firstline for classical trigeminal neuralgia. Oxcarbazepine may be preferred because of a decreased potential for drug interactions. Patients with intolerable side effects may be prescribed lamotrigine but should also be considered for a surgical intervention. For medically refractory trigeminal neuralgia early surgical therapy viz. gasserian ganglion percutaneous techniques, gamma knife and microvascular decompression may be considered. ${ }^{15,16,17,24}$

\section{Central Neuropathic Pain}

Pregabalin/ gabapentin or TCAs are recommended as first-line drugs in central neuropathic pain. Though, TCAs have been suggested in central post-stroke pain (CPSP), they may not be tolerated in elderly patients with stroke. Pregabalin has demonstrated efficacy superior to placebo in neuropathic pain due to spinal cord injuries. ${ }^{29}$ Tramadol may be considered as second-line. Strong opioids are recommended as second-line or third-line if chronic treatment is not an issue. Lamotrigine may be considered in central post-stroke pain or spinal cord injury pain with incomplete cord lesion and brushinduced allodynia. Cannabinoids are recommended in multiple sclerosis only if all other treatments fail. ${ }^{12,15}$

Table 1 summarizes the recommendations for the firstline and second line medications by the European Federation of Neurological Society (EFNS) ${ }^{15}$

Table 1: Summary of recommendations by the EFNS.

\begin{tabular}{|c|c|c|}
\hline Etiology & $\begin{array}{l}\text { Recommendations for } \\
\text { First- Line }\end{array}$ & $\begin{array}{l}\text { Recommendations for } \\
\text { Second or Third line }\end{array}$ \\
\hline $\begin{array}{l}\text { Painful Diabetic Peripheral } \\
\text { Neuropathy (PDPN) }{ }^{\mathrm{a}}\end{array}$ & $\begin{array}{l}\text { Pregabalin } \\
\text { Gabapentin } \\
\text { Duloxetine } \\
\text { TCAs } \\
\text { Venlafaxine Extended Release }\end{array}$ & $\begin{array}{l}\text { Opioids } \\
\text { Tramadol }\end{array}$ \\
\hline Post-herpetic Neuralgia (PHN) & $\begin{array}{l}\text { Pregabalin } \\
\text { Gabapentin } \\
\text { TCAs }{ }^{\text {b }} \\
\text { Lidocaine plasters }\end{array}$ & $\begin{array}{l}\text { Capsaicin patches/creams } \\
\text { Opioids }\end{array}$ \\
\hline Classical Trigeminal Neuralgia & $\begin{array}{l}\text { Carbamazepine } \\
\text { Oxcarbazepine }\end{array}$ & Surgery \\
\hline Central Neuropathic Pain & $\begin{array}{l}\text { Gabapentin } \\
\text { Pregabalin } \\
\text { TCAs }^{b}\end{array}$ & $\begin{array}{l}\text { Cannabinoids (Multiple Sclerosis) } \\
\text { Lamotrigine } \\
\text { Opioids } \\
\text { Tramadol (Spinal Cord Injury) }\end{array}$ \\
\hline
\end{tabular}

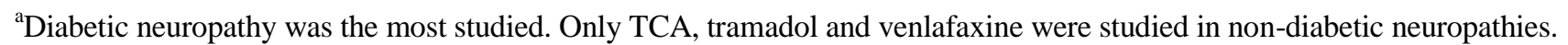
${ }^{\mathrm{b}}$ TCAs (Tricyclic Antidepressants): Amitriptyline, clomipramine, nortriptyline, desipramine, imipramine. 


\section{FIRST LINE MEDICATIONS}

\section{Tricyclic Antidepressants (TCAs)}

Primarily TCAs are antidepressants and the mechanism of analgesic action is unknown. TCAs block the reuptake of noradrenaline and serotonin. The pain relieving effect of TCAs is independent of their antidepressants effect and, thus, may be preferable for patients with co-morbid depression. They have consistently demonstrated efficacy in neuropathic pain associated with diabetes mellitus and herpes zoster. However, in randomized controlled trials of patients with neuropathy associated with spinal cord injury, HIV, neuropathic cancer pain, phantom limb pain and chronic lumbar root pain, TCAs have not demonstrated efficacy superior to placebo. The greatest advantage of TCAs could be its cost-effectiveness. The most common adverse events include sedation, anticholinergic side-effects, viz. dry mouth, constipation and urinary retention and orthostatic hypotension. TCAs can cause or exacerbate cognitive impairment and gait disturbances in elderly patients, and may predispose them to falls. TCAs are well known to be associated with cardiac toxicity and must be avoided in the elderly and in those with cardiac pathology. A screening ECG is recommended before beginning treatment with TCAs in patients over 40 years of age. Caution has to be observed to avoid accidental overdose and in patients with suicidal tendency. Lower starting dose and slower titration must be considered in a geriatric patient. ${ }^{12,13,14,16}$

\section{Selective Serotonin and Norepinephrine Reuptake Inhibitors (SNRIs): Duloxetine and Venlafaxine}

SNRIs inhibit both serotonin and norepinephrine reuptake and are primarily used as antidepressants and anxiolytics. Duloxetine is approved by the USFDA for the treatment of PDNP. It has demonstrated greater pain relief in patients with PDNP as compared to placebo irrespective of its antidepressant effects. Most common adverse reactions ( $\geq 5 \%$ and at least twice the incidence in placebo patients) are nausea, dry mouth, somnolence, constipation, decreased appetite and hyperhidrosis. Metaanalyses has shown modest increases in fasting plasma glucose in patients with PDNP but no clinically meaningful ECG changes relative to placebo in depressed patients. ${ }^{12,14,16}$

Venlafaxine has demonstrated efficacy in the treatment of PDNP and other painful neuropathies of various types, even though, it is not approved for the treatment of neuropathic pain. It has shown inconsistent results in post-mastectomy pain and various central and peripheral neuropathic pain conditions. ${ }^{12,13,14,16}$

\section{Calcium Channel alpha 2 -delta ligands: Gabapentin and Pregabalin}

Both bind to the calcium channel alpha 2 - delta subunit of voltage-gated calcium channels and result in decreased release of glutamate, norepinephrine and substance $\mathrm{P}$. Gabapentin has shown to reduce pain of peripheral diabetic neuropathy, post-herpetic neuralgia, phantom limb, diverse peripheral neuropathic pain conditions, Guillain-Barré syndrome, neuropathic cancer pain, acute and chronic spinal cord injury pain in randomized controlled trials. Apart from its pain-relieving effect, it has shown improvement in sleep, mood and healthrelated quality of life. There have been negative trials in complex regional pain syndrome type I, painful HIV neuropathy, chronic phantom and residual limb pain and chemotherapy induced neuropathy. The main doselimiting side-effects are peripheral oedema, somnolence and dizziness, which are reduced by the gradual dosage titration. Particularly in elderly patients, gabapentin can also exacerbate cognitive or gait impairment. The onset of activity can be seen as early as the second week of therapy when titration is rapid, but the peak effect usually occurs approximately two weeks after therapeutic dosage is achieved. Gabapentin requires dose reduction in renal impairment. ${ }^{12,13,14,16}$

Pregabalin has demonstrated superiority to placebo in randomized controlled trials in patients with PDPN, PHN and spinal cord injury neuropathic pain. It is recommended as a drug with strong evidence in the treatment of PDNP by the American Academy of Neurology. ${ }^{12}$ Pregabalin also demonstrates efficacy in patients with generalized anxiety disorders which may provide an additional benefit in patients with chronic pain. Pregabalin has minimal clinically relevant drug interactions and the side-effects produced are dosedependent. The potential for twice daily dosing and the linear pharmacokinetics of pregabalin may contribute to relatively greater ease of use. ${ }^{12,13,14,16}$

\section{Topical Lidocaine}

Topical lidocaine finds its place as a first-line treatment of PHN. In a meta-analysis, however, it has demonstrated only a modest effect as compared to placebo. Lidocaine patches are generally safe with a low systemic absorption and only local adverse effects (mild skin reactions) have been reported. ${ }^{12,13,14,16}$

\section{Carbamazepine and Oxcarbazepine}

Carbamazepine, primarily an antiepileptic, is recommended as a first-line treatment for the pain of trigeminal neuralgia. A study of 143 patients with trigeminal neuralgia treated with carbamazepine over a 16-year period, confirmed a sustained analgesia in patients who responded to carbamazepine and suggested that it may continue to be effective for many years. ${ }^{30}$ Oxcarbazepine is chemical structure similar to carbamazepine, but with different metabolism. Studies have confirmed that oxcarbazepine has potent antineuralgic properties in the absence of significant side effects, and, can be offered as an agent of first-choice or in those who have not responded to carbamazepine. ${ }^{31}$ 


\section{SECOND-LINE MEDICATIONS}

Second-line medications are recommended when the firstline medications are ineffective or intolerable. However, second line medications can be used as first-line in cases of acute neuropathic conditions, episodic exacerbations of severe pain, during the titration phase of first-line medication and neuropathic pain in cancer patients.

\section{Opioids}

Strong opioids (oxycodone, methadone, morphine) have established efficacy in PDPN and PHN. The most common side effects are constipation, sedation, nausea, dizziness, and vomiting; these generally decrease after long term treatment except for constipation. Cognitive impairment has been reported to be negligible to significant at very high dosages. Long-term morphine use may be associated with immunologic changes and hypogonadism while the risk of misuse or addiction, although low (2.6\%) in recent systematic studies, may be a concern with long-term use.
For these reasons, opioids are considered as second-line treatments in non-cancer neuropathic pain in all the current recommendations. $^{12,13,14,16}$

\section{Tramadol}

The efficacy of tramadol, including the combination with acetaminophen, is mainly established in PDPN. Tramadol induces dizziness, dry mouth, nausea, constipation, and somnolence and can cause or aggravate cognitive impairment, particularly in the elderly. There may be an increased risk of seizures in patients with past epilepsy, or who are receiving drugs that reduce the seizure threshold, such as TCAs. Serotonergic syndrome may occur if tramadol is used in combination with serotonergic medications (particularly SSRIs). ${ }^{12,13,14,16}$

Table 2 summarizes in brief the prescribing information for first-line medications and opioids agonists. Full prescribing information must be referred to see the complete dosing information.

Table 2: Prescribing information for selected agents for neuropathic pain.

\begin{tabular}{|c|c|c|c|}
\hline Agents & Initiating dose & Titration & Usual maintenance dose \\
\hline $\begin{array}{l}\text { TCAs } \\
\text { Nortriptyline }\end{array}$ & $10-25 \mathrm{mg} / \mathrm{day}$ & $\begin{array}{l}\text { Increase weekly by } 10-25 \\
\mathrm{mg} / \text { day as tolerated }\end{array}$ & $\begin{array}{l}50-150 \mathrm{mg} / \text { day (When given } \\
\text { above } 100 \mathrm{mg} / \text { day, plasma } \\
\text { levels of nortriptyline should } \\
\text { be monitored and maintained } \\
\text { in the optimum range of } 50 \text { to } \\
150 \mathrm{ng} / \mathrm{ml} \text { ) }\end{array}$ \\
\hline Venlafaxine & $37.5 \mathrm{mg} /$ day & $\begin{array}{l}\text { Increase weekly by } 37.5-75 \\
\text { mg/day as tolerated }\end{array}$ & $150-225 \mathrm{mg} /$ day \\
\hline Duloxetine & $30-60 \mathrm{mg} /$ day & $\begin{array}{l}\text { Increase by } 60 \mathrm{mg} / \text { day after } 1 \\
\text { week if required }\end{array}$ & $60-120 \mathrm{mg} /$ day \\
\hline Gabapentin & $100-300 \mathrm{mg} / \mathrm{day}$ & $\begin{array}{l}\text { Increase by } 300 \mathrm{mg} / \text { day every } \\
2-3 \text { days }\end{array}$ & $\begin{array}{l}900-3600 \mathrm{mg} / \mathrm{day} \text { in three } \\
\text { divided doses (reduce if renal } \\
\text { impairment) }\end{array}$ \\
\hline Pregabalin & $\begin{array}{l}75-150 \mathrm{mg} / \text { day; given } \\
\text { in two divided dosage }\end{array}$ & $\begin{array}{l}\text { Increased by } 150-300 \\
\mathrm{mg} / \text { day after an interval of } 7 \\
\text { days as tolerated }\end{array}$ & $\begin{array}{l}150-600 \mathrm{mg} / \text { day; given as } \\
\text { two divided dosage }\end{array}$ \\
\hline Carbamazepine & $\begin{array}{l}200 \mathrm{mg} / \text { day in two } \\
\text { divided dose }(100 \mathrm{mg} \\
\text { twice daily in elderly } \\
\text { patients) }\end{array}$ & $\begin{array}{l}\text { Increase by } 100 \mathrm{mg} / \text { day as } \\
\text { required }\end{array}$ & $\begin{array}{l}200-1200 \mathrm{mg} / \text { day in } 2-3 \\
\text { divided dose }\end{array}$ \\
\hline Oxcarbazepine & $\begin{array}{l}300-600 \mathrm{mg} / \text { day in } \\
\text { two divided dose }\end{array}$ & $\begin{array}{l}\text { Increase by } 300-600 \mathrm{mg} / \text { day } \\
\text { weekly as tolerated }\end{array}$ & $\begin{array}{l}300-1200 \mathrm{mg} / \text { day in two } \\
\text { divided dose }\end{array}$ \\
\hline \multicolumn{4}{|l|}{ Opioids } \\
\hline Morphine & $15 \mathrm{mg}$ every $12 \mathrm{~h}$ & & $30-120 \mathrm{mg}$ every $12 \mathrm{~h}$ \\
\hline Oxycodone & $10 \mathrm{mg}$ every $12 \mathrm{~h}$ & & $20-60 \mathrm{mg}$ every $12 \mathrm{~h}$ \\
\hline Tramadol & $50 \mathrm{mg} /$ day & $\begin{array}{l}\text { Increase by } 50-100 \mathrm{mg} / \text { day } \\
\text { in divided dose every } 3-7 \\
\text { days }\end{array}$ & $\begin{array}{l}50-100 \mathrm{mg} \text { four times a day } \\
\text { (Lower dosage in elderly } \\
\text { patients) }\end{array}$ \\
\hline
\end{tabular}




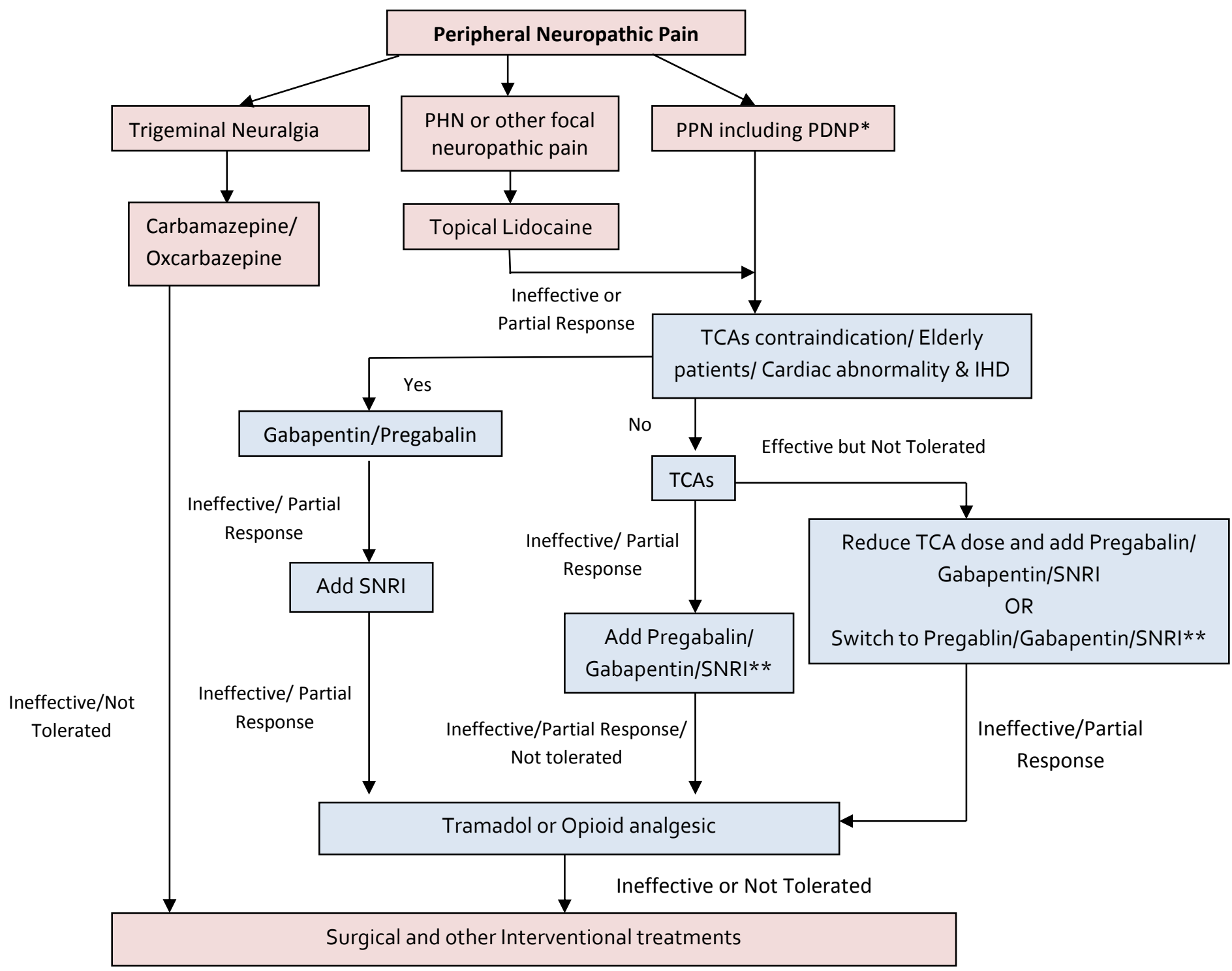

Figure 1: Algorithm for the treatment of peripheral neuropathic pain.

*This excludes HIV associated polyneuropathy. ${ }^{*}$ Second-line medications (tramadol \& opioids) must be offered only after a trial of appropriate combinations of the first-line medications for an adequate duration, at the most

effective and tolerable dose. TCAs, Tricyclic Antidepressants; SNRI, Serotonin Noradrenaline Reuptake

Inhibitors; PHN, Post Herpetic Neuralgia, PDNP; Painful diabetic neuropathic pain, PPN; Peripheral painful neuropathy, IHD; Ischemic Heart Disease.

\section{RATIONAL POLYPHARMACY: CHOOSING COMBINATIONS}

Often one drug is not sufficient due to its limited effect or dose-related side effects resulting in the use of combination medications. Though the practice of using combination medication is highly prevalent, the numbers of randomized controlled trials are few and so, a recommendation of a specific combination cannot made. The aim of rational polypharmacy should be focused at decreasing toxicity and drug interactions, addressing treatment failures and taking advantage of complementary mechanisms of actions for additive benefit. ${ }^{20,21}$ There have been various small to large studies assessing the efficacy of monotherapy vs. combination therapy with drugs of different class. In a randomized trial of 57 patients with PDNP and PHN, combining gabapentin with morphine demonstrated small but significantly superior benefits versus gabapentin and morphine alone. ${ }^{22}$ In a 6 week randomized study comparing gabapentin vs. nortriptyline vs. combination in patients with PDNP and PHN, the combination treatment demonstrated superior pain control than the individual drugs. In another study involving patients with various neuropathic conditions, viz. PHN, PDNP, spinal stenosis and radiculopathy, the combination of pregabalin and oxycodone controlled release was more effective in improving pain and quality of life than pregabalin. 
However, a recent study showed that the addition of a low dose of oxycodone at $10 \mathrm{mg} /$ day did not enhance the pain-relieving effects of pregabalin in patients with PDNP and PHN. ${ }^{32,33}$ There is a general consensus that combination therapy may be superior for controlling pain as compared to the individual drugs, however, it must be offered only after an adequate trial of first-line monotherapy fails or is intolerable at the maximum effective dosage.

\section{WHAT TO CHOOSE AND WHEN?}

Given the diversity of choices amongst the first-line agents, it is important that the first therapeutic choice made yields the best results. The choice of the first-line agent should not be on the mechanism of action. Since, direct comparative trials are not available, reviews in the past have used the NNT (number needed to treat to obtain one patient with more than $50 \%$ pain relief) and $\mathrm{NNH}$ (number needed to harm) to estimate relative efficacy and side-effects of the drugs. In an analysis, the NNT for all neuropathic pain conditions for the class of antidepressants was 3.3 (2.9-3.8), for TCA 3.1 (2.7-3.7) and for SNRIs 5.5 (3.4-14). The NNT for gabapentin/pregabalin was $4.7(4.0-5.6)$; for opioid, 2.5 (2.0- 3.2) and for tramadol, 3.9 (2.7-6.7). The NNH for TCAs was 14.7 (10-25), for gabapentin/pregabalin, 17.8 (12-30), for opioid, 17.1 (10-66) and for tramadol, 9 (6$18)$. If analgesia is the only criterion for selection, then the chronology of preference would probably be TCAs> opioids $\geq$ tramadol $\geq$ gabapentin/pregabalin. If the tolerability to the drugs and the related effect on the quality of life of the patient is considered, then the likely preference would be gabapentin/pregabalin > tramadol/ opioids > TCAs. $^{19}$

Figure 1 illustrates an algorithm or the pharmacological treatment for peripheral neuropathic pain based on the available evidence and recommendations. ${ }^{15-21}$

\section{NON-PHARMACOLOGICAL THERAPY}

Non-pharmacological treatments are divided into physical, surgical and psychological treatment. Some physical treatments include physiotherapy, stimulation and nerve blocking techniques. Destruction of nociceptive fibres and their dorsal root entry zones are a part of surgical modality of treatment. Psychological methods (relaxation, hypnosis) are useful to reduce anxiety and neurovegitative hypertonicity, which aggravates neuropathic pain. It aims at modifying the pain perception by helping patients develop self-management strategies. $^{23}$

\section{CONCLUSION}

Chronic neuropathic pain is a debilitating symptomatology of lesions/injuries of the nervous system. TCAs, SNRIs, pregabalin, gabapentin are recommended as first-line therapeutic agents. Lidocaine plasters are recommended as first-line for PHN and other focal neuropathies. Based on the NNT and NNH values, it is likely that TCAs might offer best analgesic efficacy as first-line agents in most of the peripheral neuropathic conditions with the exception of HIV- associated polyneuropathy, which is resistant to the first-line medications. However, if the adverse event profile and the related effect on the quality of life are considered, then, either gabapentin or pregabalin might be a preferable first-line option. Tramadol and opioids are considered to be second-line treatment. The practice of combinations is highly prevalent in the management of neuropathic pain. Due to paucity of adequate comparative trials, recommendation for a specific combination cannot be made. However, rational polytherapy must aim at addressing treatment failure, improving side-effect profile, minimizing risk of drug interactions and taking advantage of different mechanisms of action of the agents. Non-pharmacological treatment must be a considered at any stage of management and the therapy must be individualized.

\section{Funding: No funding sources \\ Conflict of Interest: Affiliation with Cipla Ltd as a Medical Advisor}

\section{REFERENCES}

1. Woolf CJ. Pain: moving from symptom control toward mechanism-specific pharmacologic management. Ann Intern Med 2004;140:441-51.

2. Treede RD, Jensen TS, Campbell JN, Cruccu G, Dostrovsky JO, Griffin JW, et al. Neuropathic pain. Redefinition and a grading system for clinical and research purposes. Neurology 2008;70:1630-5.

3. Dieleman JP, Kerklaan J, Huygen FJ, Bouma PA, Sturkenboom MC. Incidence rates and treatment of neuropathic pain conditions in the general population. Pain 2008;137:681-8.

4. Torrance N, Smith BH, Bennett MI, Lee AJ. The epidemiology of chronic pain of predominantly neuropathic origin. Results from a general population survey. J Pain 2006;7:281-9.

5. Bouhassira D, Lanteri-Minet M, Attal N, Laurent B, Touboul C. Prevalence of chronic pain with neuropathic characteristics in the general population. Pain 2008;136:380-7.

6. Schmader KE. Epidemiology and impact on the quality of life of postherpetic neuralgia and painful diabetic neuropathy. Clin J Pain 2002;18:350-4.

7. Tesfaye S, Stevens LK, Stephenson JM, Fuller JH, Plater M, Ionescu-Tirgoviste C, et al. Prevalence of diabetic peripheral neuropathy and its relation to glycaemic control and potential risk factors: the EURODIAB IDDM Complications Study. Diabetologia 1996;39:1377-84.

8. Young MJ, Boulton AJ, MacLeod AF, Williams DR, Sonksen PH. A multicentre study of the prevalence of diabetic peripheral neuropathy in the United Kingdom hospital clinic population. Diabetologia 1993;36:150-4. 
9. Gonzalez-Duarte A. Robinson-Papp J, Simpson DM. Diagnosis and management of HIV-associated neuropathy. Neurol Clin 2008;26:821-32.

10. Sadosky A, McDermott AM, Brandenburg NA, Strauss M. A Review of the Epidemiology of Painful Diabetic Peripheral Neuropathy, Postherpetic Neuralgia, and Less Commonly Studied Neuropathic Pain Conditions. Pain Pract 2008;8:45-56.

11. Galluzzi KE. Managing Neuropathic Pain. J Am Osteopath Assoc 2007;107:ES39-48.

12. Dworkin RH, O'Connor AB, Backonja M, Farrar JT, Finnerup NB, Jensen TS, et al. Pharmacologic management of neuropathic pain: Evidence-based recommendations. Pain 2007;132:237-51.

13. Finnerup NB, Sindrup SH, Jensen TS. The evidence of pharmacological treatment of neuropathic pain. Pain 2010;150:573-81.

14. Moulin DE, Clark AJ, Gilron I, Ware MA, Watson CP, Sessle BJ, Coderre T, et al. Pharmacological management of chronic neuropathic pain Consensus statement and guidelines from the Canadian Pain Society. Pain Res Manage 2007;12:13-21.

15. Attal N, Cruccua G, Barona R, Haanpaa M, Hanssona $\mathrm{P}$, Jensen TS, Nurmikko T. EFNS guidelines on the pharmacological treatment of neuropathic pain: 2010 Revision. Eur J Neurol 2010;17:1113-e88.

16. Dworkin RH, O'Connor AB, Audette J, Baron R, Gourlay GK, et al. Recommendations for the Pharmacological Management of Neuropathic Pain: An Overview and Literature Update. Mayo Clin Proc 2010;85:S3-S14.

17. Bril V, England J, Franklin GM, Backonja M, Cohen J, Del Toro D, et al. Evidence-based guideline: Treatment of painful diabetic neuropathy. Neurology 2011;76:1758-65.

18. Ian Gliron, C. Peter N. Watson, Catherine M. Cahill, Dwight E. Mouline. Neuropathic pain; a practical guide for the clinician. CMAJ 2006;175:265-75.

19. Finnerup NB, Otto M, McQuay HJ, Jensen TS, Sindrup SH. Algorithm for neuropathic pain treatment: an evidence based proposal. Pain 2005;118:289-305.

20. Argoff CE, Backonja MM, Belgrade MJ, Bennett GJ, et al. Consensus Guidelines: Treatment Planning and Options. Mayo Clin Proc 2006;81(4 Suppl):S12-25.

21. Chaparro LE, Wiffen PJ, Moore RA, Gilron I. Combination pharmacotherapy for the treatment of neuropathic pain in adults. Cochrane Database Syst Rev 2012;7:CD008943.

22. Ian Gilron, Joan M. Bailey, R.N., DongshengTu, Ronald R. Holden,Donald F. Weaver, Robyn L.
Houlden. Morphine, Gabapentin, or Their Combination for Neuropathic Pain. N Engl J Med 2005;352:1324-34.

23. Guastella V, Mick G, Laurent B. Non pharmacologic treatment of neuropathic pain. Presse Med 2008;37(2 Pt 2):354-7.

24. Cruccu G, Gronseth G, Alksne J, Argoff C, Brainin $\mathrm{M}$, Burchiel $\mathrm{K}$, et al. American Academy of Neurology Society; European Federation of Neurological Society. AAN-EFNS guidelines on trigeminal neuralgia management. Eur $\mathbf{J}$ Neurol 2008;15:1013-28.

25. Abrams DI, Jay CA, Shade SB, Vizoso H, Reda H, Press S, et al. Cannabis in painful HIV-associated sensory neuropathy: a randomized placebocontrolled trial. Neurology 2007;68:515-21.

26. Ellis RJ, Toperoff W, Vaida F, van den Brande G, Gonzales J, Gouaux B, Bentley H, Atkinson JH. Smoked medicinal cannabis for neuropathic pain in HIV: a randomized, crossover clinical trial. Neuropsychopharmacology 2009;34:672-80.

27. Simpson DM, Brown S, Tobias J. Controlled trial of high-concentration capsaicin patch for treatment of painful HIV neuropathy. Neurology 2008;70:230513.

28. Simpson DM, McArthur JC, Olney R, Clifford D, So Y, Ross D, Baird BJ, et al. Lamotrigine HIV Neuropathy Study Team. Lamotrigine for HIV associated painful sensory neuropathies: a placebocontrolled trial. Neurology 2003;60:1508-14.

29. Siddall PJ, Cousins MJ, Otte A, Griesing T, Chambers R, Murphy TK. Pregabalin in central neuropathic pain associated with spinal cord injury, a placebo-controlled trial. Neurology 2006;67:1792800.

30. Taylor JC, Brauer S, Espir ML. Long-term treatment of trigeminal neuralgia with carbamazepine. Postgrad Med J 1981;57:16-8.

31. Gomez-Arguelles JM, Dorado R, Sepulveda JM, Herrera A, et al. Oxcarbazepine monotherapy in carbamazepine-unresponsive trigeminal neuralgia. J Clin Neurosci 2008;15:516-9.

32. Vorobeychik Y, Gordin V, Mao J, Chen L. Combination Therapy for Neuropathic Pain. A Review of Current Evidence. CNS Drugs 2011;25:1023-34.

33. Zin CS, Nissen LM, O'Callaghan JP, et al. A randomized controlled trial of oxycodone versus placebo in patients with post-herpetic neuralgia and painful diabetic neuropathy with pregabalin. J Pain 2010;11:462-71.

doi:10.5455/2319-2003.ijbcp20130601

Cite this article as: Ansari Z. Evidence-based

pharmacological management of chronic neuropathic pain. Int J Basic Clin Pharmacol 2013;2:229-36. 